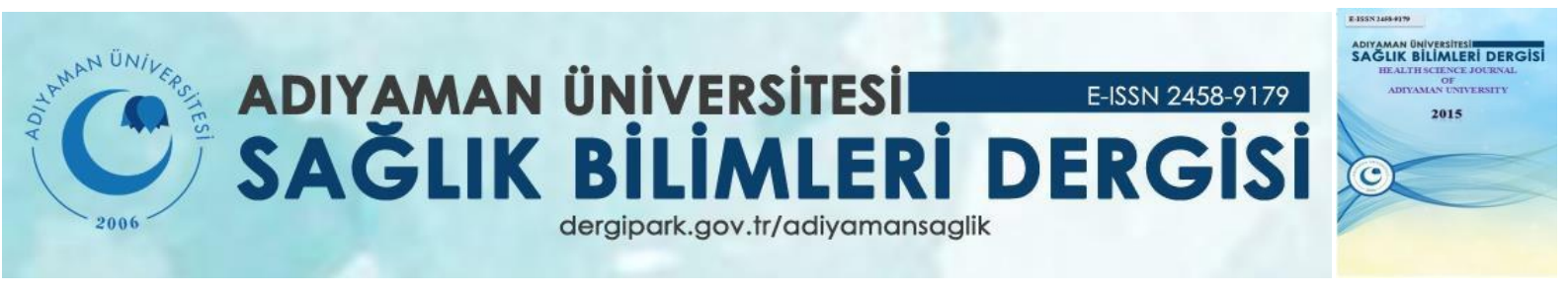

Araştırma/Research

\title{
Diş Hekimliği Fakültesi Öğrencilerinin Dental Kaygı Seviyelerinin Karşılaştırılması
}

\author{
Fatih AKSOY ${ }^{1}$
}

1 Adıyaman Üniversitesi Diş Hekimliği Fakültesi Endodonti Anabilim Dalı, Adıyaman, Türkiye, dr.f.aksoy@gmail.com / ORCID : 0000-0002-2782-2608

\section{$\ddot{\mathbf{O Z}}$}

Amaç: Bu çalışmanın amacı diş hekimliği fakültesinde eğitim gören birinci ve dördüncü sınıf öğrencilerin dental kaygı düzeylerinin karşılaştırılmasıdır.

Yöntem: Çalışmamıza diş hekimliği fakültesinde eğitim gören 82 birinci sınıf, 45 dördüncü sınıf olmak üzere toplamda 127 öğrenci dahil edilmiştir. Dental kaygının ölçülmesi için sıklıkla kullanılan 5 sorudan oluşan Modifiye Dental Anksiyete Skalasını (MDAS) ve demografik bilgileri içeren anket formları katılımcılara dağıtıldı. MDAS skoru 19 veya daha yüksek olan katılımcılar yüksek dental kaygı düzeyine sahip olarak değerlendirildi ve kaydedildi. Elde edilen verilerin Student t testi ile tek yönlü varyans analizi (ANOVA) kullanılarak istatistiksel analizleri yapıldı.

Bulgular: Tüm sorularda birinci sınıfların MDAS skorları daha yüksekti ve ilk soru hariç diğer tüm sorularda skorlar bakımından gruplar arasında anlamlı fark bulundu $(\mathrm{p}<0.001)$. Birinci sinıflarda elde edilen ortalama MDAS skoru (14.28 \pm 4.09$)$ dördüncü sinıflarda elde edilen ortalama MDAS skoruna (10.59 \pm 3.67$)$ göre anlamlı derecede daha yüksek bulundu $(\mathrm{p}<0.001)$. MDAS skoru $\geq 19$ olan öğrenci sayısı birinci sınıflarda $10(\% 12,2)$ iken dördüncü sınıflarda 1 $(\% 2,2)$ olarak bulundu.

Sonuç: Diş hekimliği birinci sınıfta eğitim gören öğrencilerin düzeyleri dördüncü sınıfta eğitim gören öğrencilere göre daha yüksektir. Diş hekimliği eğitimi ile dental kaygı arasında ters orantı olduğu görülmüştür. $\mathrm{Bu}$ veriler doğrultusunda diş işlemleriyle alakalı bilgilendirmenin arttırılarak bireylerin dental kaygı düzeylerinin azaltılabileceği söylenebilir.

Anahtar Kelimeler: Dental Kaygı; Diş Hekimliği Öğrencisi; Dental Anksiyete Skalası

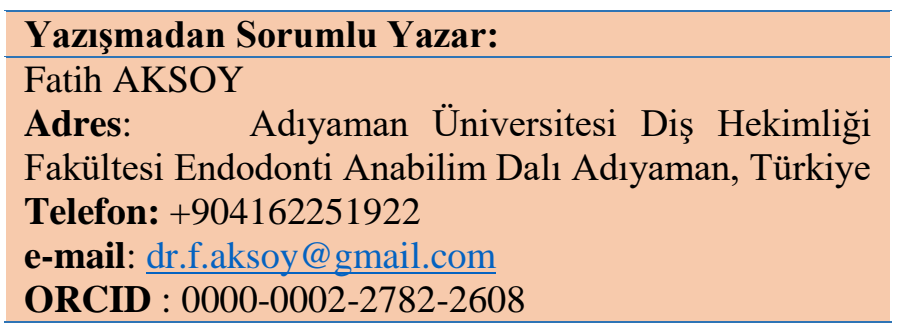

\section{Doi: 10.30569.adiyamansaglik.648049}

Atıf Gösterimi/How to Cite: Aksoy F. Diş Hekimliği Fakültesi Öğrencilerinin Dental Kayg1 Seviyelerinin Karşılaştırılması. Adıyaman Üni. Sağlık Bilimleri Derg. 2019; 5(3); 1767 -1775. doi: 10.30569.adiyamansaglik.648049 


\section{Comparison of Dental Anxiety Levels of Dentistry Students}

\section{ABSTRACT}

Objective: The aim of this study was to compare the levels of dental anxiety among the first and fourth year dentistry students.

Methods: A total of 127 dentistry students (82 first year and 45 fourth year) were enrolled in the study. Questionnaire forms including Modified Dental Anxiety Scale (MDAS) and demographic information, consisting of 5 questions frequently used for measuring dental anxiety, were distributed to the participants. Participants with an MDAS score of 19 or higher were evaluated as having a high level of dental anxiety and were recorded. The data were analyzed by Student $t$ test and ANOVA.

Results: The MDAS scores of the first year student were higher in all questions and there was a significant difference between the groups in terms of scores in all other questions except the first question $(\mathrm{p}<0.001)$. The mean MDAS score in the first year $(14.28 \pm 4.09)$ was significantly higher than the mean MDAS score in the fourth year $(10.59 \pm 3.67)(\mathrm{p}<0.001)$. The number of students with MDAS score $\geq 19$ was $10(12.2 \%)$ in the first year and $1(2.2 \%)$ in the fourth year.

Conclusion: First year dentistry students have higher levels than fourth year students. There was an inverse relationship between dental education and dental anxiety. According to these data, it can be said that dental anxiety levels of individuals can be decreased by increasing the information about dental procedures.

Key Words: Dental Anxiety; Dentistry Student; Dental Anxiety Scale

\section{GíRiş}

Diş hekimi ve diş tedavileri ile ilgili korku ve kaygı(anksiyete) birçok hasta için sorun teşkil etmekte, hatta kaygı düzeyi çok arttığında hastalar acil yapılması gereken tedavilerden dahi kaçınmaktadırlar. Korku daha çok subjektif bir duygu hali olup, bilinen tehlikelere karşı gösterilen tepki iken, kaygı şahsiyetin bütünlüğünün tehdit edildiği, daha çok geleceğe yönelik olan, herhangi bir durumda ortaya çıkan ve korkunun daha genel ve bilinmeyenine karşı olan şeklidir $(1,2)$. Yaşam boyunca birçok faktöre karşı korku ve kaygı gelişebilmektedir. Dental anksiyete terimi diş hekimliği literatüründe bireylerin her türlü diş tedavisine karşı hissettiği kaygıyı ifade etmektedir (3). Diş hekimliğinde son yıllardaki teknolojik gelişmeler ve konfor 
düzeyi arttırılmış tedavi şekillerine rağmen dental uygulamalara karşı duyulan kaygı hala yaygindir (4).

Türkiye'de hastaların \%8,8'inin (5), diğer ülkelerde ise \%4,2 ile \%20,9 aralığında değişen oranlarda yüksek düzeyde dental kaygıya sahip oldukları belirtilmektedir (6,7). Dental uygulamalara ve bunun yanında uygulamayı yapan hekimlere karşı duyulan kaygı birçok faktör tarafından etkilenen oldukça karışık bir durumdur. Diş tedavileri ile ilgili kaygıların oluşmasında hastaların yaşadıkları ortam, psikolojik etkenler, yaşları, cinsiyetleri, eğitim durumları ve bunların yanında diş tedavileri ile ilgili geçmişte yaşadıkları olumsuz tecrübeler gibi farklı etkenlerin etkisi olduğu bilinmektedir (8-10). Ayrıca ailedeki bireylerden veya yakın çevreden dişhekiminin yaklaşımını ve diş tedavisi ile ilgili olumsuz yorumları ve sergilenen kaygılı davranışları gözlemlemekte dental kaygı oluşumundaki etkenler arasındadır (3).

Dental kaygılar hem hastalar hem de hekimler için en önemli problemeler arasında yer almaktadır. Kaygılı hastanın duygusal durumu ve buna bağlı tedavi sırasında sergilediği fiziksel aktivite hekimin de kaygılanmasına bunun yanında etkin ve sağlıklı bir tedavi yapmasına engel olmaktadır. Bu durumun temel sebeplerini ortaya koyarak hastaların kaygılarının azaltılması veya yok edilesine yönelik çalışmalar mevcuttur. Diş tedavileri ile ilgili kaygının sebeplerinin araştırıldığı çalışmalarda yaş, cinsiyet, yapılacak olan tedavinin türü ile eğitim düzeyi gibi pek çok faktör değerlendirilmiştir (11-14). Eğitim seviyesiyle dental kaygının ters orantılı olduğunu ve alınan eğitimin türünün de dental kaygı seviyesi üzerine etkisinin olduğunu gösteren çalışmalar mevcuttur (11-13).

Bu bilgiler doğrultusunda çalışmamızın amacı diş hekimliği fakültesinde eğitime yeni başlamış ve diş hekimliğiyle ilgili o güne kadar edindiği genel bilgiler ve tecrübeler dışında detaylı teorik veya pratik bilgisi bulunmayan birinci sınıf öğrencileri ile diş hekimliğine ve dental uygulamalara yönelik teşhis ve tedaviyi yapabilecek kadar bilgi birikime sahip olan dördüncü sınıf öğrencilerinin dental kaygı düzeylerinin karşılaştırılmasıdır. Sonuçlar doğrultusunda diş hekimliği uygulamalarıyla alakalı bilgi düzeyinin dental kaygı üzerinde etkili olup olmadığının tespit edilmesi ve buna yönelik çözümlerin sunulması amaçlanmaktadır.

\section{GEREÇ VE YÖNTEM}

Çalışmamıza Adıyaman Üniversitesi Diş Hekimliği Fakültesi birinci sınıfında (n=82) ve dördüncü sınıfında $(n=45)$ eğitim gören toplamda 127 öğrenci dahil edilmiştir ve Adiyaman Üniversitesi Girişimsel Olmayan Klinik Araştırmalar Etik Kurulu tarafından onaylandıktan sonra başlanmıştır (Onay No: 2019/8-24). Öğrencilere çalışmayla alakalı bilgi verildikten sonra 
bilgilendirilmiş gönüllü onam formunu onaylayarak çalışmaya katılmayı kabul eden 127 öğrenciye anket formları dağıtıldı. Anket formu demografik bilgiler ile dental kaygının ölçülmesinde sıklıkla kullanılan Modifiye Dental Anksiyete Skalasından (MDAS, Şekil 1) oluşmaktaydı (15).

Şekil 1. Modifiye Dental Anksiyete Skalası

\title{
Lütfen aşağıda sralanmıș 5 soru için size en uygun seçeneği işaretleyin.
}

\author{
1. Eğer tedavi için yarın diş hekiminize gidecek olsaydınız, nası hisseder diniz? \\ a. Eğlenceli bir deneyim olacağını düşünürüm \\ b. Umursamam \\ c. Çok az huzursuz olurum \\ d. Hoş olmayan tatsız ve ağrılı bir durum olduğunu düşündüğümden biraz korkarım \\ e. Diş hekimi ne yapacak diye çok korkarım
}

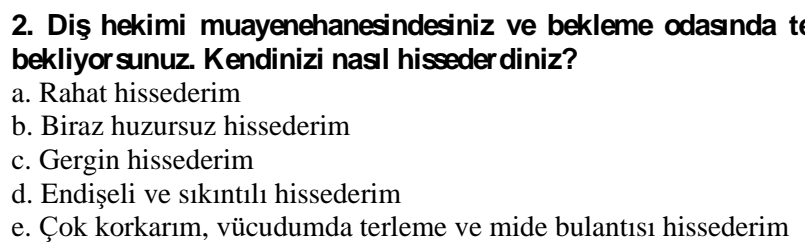

3. Dişhekiminin koltuğuna oturdunuz ve doktorunuzun dişinize tedavi yapmak için dönen aletleri hazırlamasnı bekliyorsunuz. Nasıl hissederdiniz?

(2. Sorunun yanıtı için verilen şıkların aynısı)

\section{Diş hekiminin koltuğuna oturdunuz ve doktorunuzun diş taşlarınızı temizlemek için kazıyıcı aletleri hazırlamasını bekliyorsunuz. Nası hissederdiniz? \\ (2. Sorunun yanıtı için verilen şıkların aynısı) \\ 5. Diş hekiminiz üst dişinizin dişetine enjeksiyon (iğne) yapmak üzere olsa kendinizi nası hissederdiniz? \\ (2. Sorunun yanıtı için verilen şıkların aynısı)}

Öğrencilere sorulara içtenlikle cevap vermeleri tavsiye edildi. MDAS 5 sorudan ve her soru için 5 seçenekten oluşan ve 1-5 arası skorlaması olan cevapları içermektedir. Her soruya verilen cevaba göre skorlar toplanarak toplamda 5 (anksiyete yok) ile 25 (yüksek anksiyete) arası değişebilen skorlar her bir katılımcı için bulunduğu sınıf dikkate alınarak kaydedildi. MDAS skoru 19 veya daha yüksek olan katılımcılar yüksek dental kaygı düzeyine (Dental Fobi) sahip olarak değerlendirilmeye alındı ve kaydedildi.

Elde edilen veriler SPSS programına (SPSS Inc., Chicago, IL, ABD) aktarıldı ve Student t testi ile tek yönlü varyans analizi (ANOVA) kullanılarak istatistiksel analizleri yapıldı. $p<0.05$ değeri istatistiksel olarak anlamlı kabul edildi.

\section{BULGULAR}

Çalışmaya katılan birinci sınıftaki 82 öğrencinin 42'si kızlardan, 40’1 erkeklerden oluşmaktaydı. Dördüncü sınıftaki 45 öğrenciden ise 25'i kılardan, 20'si erkeklerden 
oluşmaktaydı ve gruplar arasında cinsiyet açısından anlamlı bir fark bulunmadı. Birinci ve dördüncü sınıftaki öğrencilerin yaş ortalaması sırasıyla 19.07 (18-23) ve 21.82 (18-24) olarak bulundu ve dördüncü sınıftaki öğrencilerin yaş ortalamasının anlamlı düzeyde daha yüksek olduğu tespit edildi $(\mathrm{p}<0.001)$ (Tablo 1$)$.

Tablo 1. Öğrencilerin demografik bilgileri ve MDAS $\geq 19$ oranı

\begin{tabular}{|c|c|c|}
\hline & $\begin{array}{c}\text { 1. Sinıf } \\
(\boldsymbol{n = 8 2})\end{array}$ & $\begin{array}{c}\text { 4. Sinıf } \\
(\mathbf{n = 4 5})\end{array}$ \\
\hline Cinsiyet K/E & $42 / 40$ & $25 / 20$ \\
\hline Yas & $19,07 \pm 0,96(18-23)$ & $21,82 \pm 0,77(18-24)$ \\
\hline MD $\boldsymbol{A S} \geq \mathbf{1 9}$ & $10(\% 12,2)$ & $1(\% 2,2)$ \\
\hline
\end{tabular}

Ankete katılan birinci ve dördüncü sınıf öğrencilerin her soru için ortalama ve toplam skorları Tablo 2'de verilmiştir. En yüksek anksiyete seviyesi birinci sınıf için dental anestezi yapılması (3.61 \pm 1.01$)$ düşüncesinde bulundu, dördüncü sınıflarda ise diş hekimine gitme düşüncesinde (2.51 \pm 0.89$)$ tespit edildi. Tüm sorularda birinci sınıfların MDAS skorları daha yüksekti ve ilk soru hariç diğer tüm sorularda skorlar bakımından gruplar arasında anlamlı fark bulundu $(\mathrm{p}<0.001)$. Birinci sinıflarda elde edilen ortalama MDAS skoru $(14.28 \pm 4.09)$ dördüncü sinıflarda elde edilen ortalama MDAS skoruna (10.59 \pm 3.67 ) göre anlamlı derecede daha yüksek bulundu $(\mathrm{p}<0.001)$ (Tablo 2$)$. MDAS skoru $\geq 19$ olan öğrenci sayısı birinci sınıflarda $10(\% 12,2)$ iken dördüncü sinıflarda $1(\% 2,2)$ olarak bulundu.

Tablo 2. Öğrencilerin ortalama MDAS skorları

\begin{tabular}{|c|c|c|}
\hline & $\begin{array}{c}\text { 1. Sinıf } \\
(\boldsymbol{n = 8 2})\end{array}$ & $\begin{array}{c}\text { 4. Sinıf } \\
(\boldsymbol{n = 4 5 )})\end{array}$ \\
\hline Soru 1 & $2,78 \pm 1,1$ & $2,51 \pm 0,89$ \\
\hline Soru 2 & $2,49 \pm 0,89$ & $1,86 \pm 0,97$ \\
\hline Soru 3 & $2,61 \pm 0,99$ & $1,91 \pm 0,91$ \\
\hline Soru 4 & $2,8 \pm 0,91$ & $1,89 \pm 0,91$ \\
\hline Soru 5 & $3,61 \pm 1,01$ & $2,42 \pm 1,01$ \\
\hline Toplam & $14,28 \pm 4,09$ & $10,59 \pm 3,67$ \\
& $(7-24)$ & $(5-21)$ \\
\hline
\end{tabular}




\section{TARTIŞMA}

Dental işlemlere yönelik yüksek kaygı seviyesi hastalarda ağız diş sağlığını olumsuz yönde etkilemekte ve hastalar diş hekiminin sağlayacağı tedavilerden faydalanamamaktadır, böylece yaşam kalitelerinde de dental kaygıdan kaynaklanan olumsuz etkiler oluşmaktadır. Dental kaygının tespiti ve yaşam kalitesi üzerine etkilerini araştıran çok sayıda çalışma mevcuttur $(16,17)$. Dental anksiyete seviyesinin belirlenmesinde tercih edilen ölçekler genellikle Corah Dental Anksiyete Skalası (CDAS) ve Modifiye Dental Anksiyete Skalasıdır (MDAS) $(18,19)$. CDAS dört sorudan oluşan, hastalar tarafindan kolay anlaşılabilen ve uygulaması da bu yönde kolay olan bir skala olmasına rağmen, lokal dental anestezi enjeksiyonu ile ilgili bir soru içermemektedir. Çalışmamızda tercih ettiğimiz MDAS ise CDAS'a ağız içi enjeksiyonla alakalı kaygı seviyesini belirlemeye yönelik bir sorunun eklenmesiyle elde edilmiş beş sorudan oluşan skorları 5-25 arasında değişen modifiye bir dental anksiyete tespit skalasıdır $(15,18)$. Humphris ve ark. (15), dental enjeksiyonunun en kaygı verici durum olduğunu bildirmişlerdir, lokal anestezi kaygısı hastalar arasında yaygın olduğundan dolayı biz de çalışmamızda bu kaygının skorunu tespit edebilmek için MDAS kullanmayı tercih ettik.

Diş hekimliği birinci sınıf eğitimine başlayan öğrenciler diş hekimliği alan derslerini ilerleyen sınıflarda daha yoğun alacaklarından dolayı geleneksel dental bilgileri dışında diş hekimliği ve uygulamaları konusunda detaylı bilgiye sahip değillerdir. Diş hekimliği dördüncü sınıf öğrenciler ise yıllar içerisinde diş hekimliği alanı ile ilgili teorik/pratik eğitim alarak ve klinikte hasta bakmaya başlayarak diş hekimliği ve uygulamaları konusunda oldukça detaylı bilgiye sahip olmaktadırlar. Eğitim düzeyiyle dental kaygının ilişkili olduğunu gösteren çok sayıda çalışma mevcuttur (11-13). Biz de çalışmamıza birinci ve dördüncü sınıf öğrencileri dahil ederek diş ile ilgili işlemlere karşı duyulan kaygının bu konudaki bilgi düzeyi arttıkça değişip değişmediğini tespit etmek istedik.

İlgüy ve ark. (5) MDAS'ın türk toplumunda güvenilirliğini ve geçerliliğini araştırdıkları çalışmalarında $\geq 19$ skora sahip hastaları dental fobiye sahip olarak değerlendirmişler ve skalanın uygun hassasiyet ve özgünlüğe sahip olduğunu belirtmişlerdir. Aynı çalışmada yüksek dental kaygıya sahip hastaların oranını ise \%8,8 olarak rapor etmişlerdir. Fransa'da yetişkin bireylerin \%7,3'ünün yüksek dental kaygıya sahip olduğu ve kırsal bölgelere gidildikçe ve eğitim seviyesi azaldıkça bu kaygının arttığı bildirilmiştir (11). Kanada'da ise popülasyonun \%5,5’inin yüksek düzeyde dental kaygıya sahip olduğu bildirilmiştir (7). 
Humphris ve ark. (15) 2009 yılında yetişkin bireylerde gerçekleştirdiği araştırmada, diş ile ilgili işlemlerde yüksek düzeyde kaygıya sahip olanların oranını \%11,6 olarak bulmuştur. Halonen ve ark. (20) ise 2012 yllında Finlandiya'da toplam 880 üniversite öğrencisi ile gerçekleştirdikleri araştırmalarında dental kaygıya sahip öğrencilerin oranını \%11,3 olarak bildirilmişlerdir. Öğrenciler üzerinde yapılan bir diğer araştırmada ise Kaakko ve ark. (21) ABD'de üniversitede eğitim gören öğrencilerin \%19'unda yüksek dental kaygı tespit edildiğini belirtmişlerdir. Diş hekimliği öğrencileri ile tıp ve mühendislik fakültesi öğrencilerinin dental kaygı düzeylerinin araştırıldığı bir çalışmada, diş hekimliği fakültesi öğrencilerinin dental anksiyete seviyelerinin daha düşük olduğu belirtilmiştir (12).

Arslan ve ark. (22) diş hekimliğgi birinci, ikinci ve üçüncü sınıf öğrenciler üzerinde yaptıkları dental anksiyete ve ağız sağlığı çalışmalarında sınıf seviyesi arttıkça dental işlemlere karşı hissedilen kaygının azaldığını bildirmişlerdir. Diş hekimliği birinci ve son sınıf öğrencilerinin dental kaygı düzeyini değerlendiren diğer bir çalışmada birinci sınıftaki öğrencilerin \%10,4'ünün dördüncü sınıftaki öğrencilerin ise \%1,8'inin MDAS skorunun $\geq 19$ olduğu ve yüksek düzeyde dental kaygılarının olduğu bildirilmiştir (23). Ayrıca toplam MDAS skorlarının birinci ve son sınıfta sirasıyla 12,52 ve 10,16 olduğu ve gruplar arası farkın anlamlı olduğu belirtilmiştir. Bu çalışmalarla uyumlu olarak bizim çalışmamızda da dental anksiyete düzeyi birinci sınıflarda $(14,28 \pm 4,09)$ dördüncü sınıflara $(10,59 \pm 3,67)$ göre daha yüksek bulunmuştur. MDAS skoru $\geq 19$ olan yüksek anksiyete seviyesine sahip öğrencilerin oranı önceki çalışmayla benzer şekilde birinci sinıflarda \%12,2 iken dördüncü sınıflarda sadece \%2,2 bulunmuştur ve anlamlı fark tespit edilmiştir. En yüksek kaygı düzeyi birinci sınıflarda dental anestezide dördüncü sınıfta ise diş hekimine gitme düşüncesinde ortaya çıktığını, tüm sorularda birinci sınıfların dördüncü sınıflara göre daha yüksek MDAS skorlarına sahip olduğunu tespit ettik.

Önceki çalışmalarda olduğu gibi mevcut çalışmada da eğitim seviyesi ile dental kaygı arasında ters orantı olduğu görülmüştür. Dördüncü sınıfta eğitim gören öğrencilerin dental kaygılarının anlamlı derecede daha az olmasının nedeninin dental uygulamalar konusundaki bilincin artması ve dental uygulamaların düşünüldüğü kadar ağrılı ve kaygı verici olmadığının anlaşılmış olmasından kaynaklandığını düşünmekteyiz. Bu veriler doğrultusunda diş işlemleriyle alakalı bilgilendirmenin küçük yaşlardan itibaren daha detaylı yapılması ve gerektiğinde hastaların diş ile alakalı işlemleri gözlemlemesi sağlanarak dental kaygı düzeylerinin azaltılabileceğini ve hayat kalitelerinin bu yönde arttırılabileceğini söyleyebiliriz. 


\section{KAYNAKLAR}

1. Brown DF, Wright FA, McMurray NE. Psychological and behavioral factors associated with dental anxiety in children. J Behav Med 1986; 9(2):213-218.

2. Freeman RE. Dental anxiety: A multifactorial aetiology. Br Dent J 1985;159(12):406-408.

3. Ter Horst G, De With CA. Review of behavioural research in dentistry 1987-1992. dental anxiety, dentistpatient relationship, compliance and dental attendance. Int Dent J 1993;43(3): 265-78.

4. Akarslan ZZ, Erten H. Diş hekimliği korkusu ve kaygısı. Hacettepe Diş Hek Fak Derg 2009;33(1):62-8.

5. Ilgüy D, Ilgüy M, Dinçer S, Bayirli G. Reliability and validity of the Modified Dental Anxiety Scale in Turkish patients. J Int Med Res. 2005;33(2):252-9.

6. Dionne RA, Gordon SM, McCullagh LM, Phero JC. Assessing the need for anesthesia and sedation in the general population. J Am Dent Assoc 1998;129(2):167-73.

7. Chanpong B, Haas DA, Locker D. Need and demand for sedation or general anesthesia in dentistry: a national survey of the Canadian population. Anesth Prog 2005;52(1):3-11.

8. Muğlalı M, Kömerik N. Ağız cerrahisi ve anksiyete. Cumhuriyet Ü Diş Hek Fak Derg 2005;8(2):83-8.

9. Kanegane K, Penha SS, Munhoz CD, Rocha RG. Dental anxiety and salivary cortisol levels before urgent dental care. J Oral Sci 2009;51(4):515- 20.

10. Locker D, Thomson WM, Poulton R. Psychological disorder, conditioning experiences, and the onset of dental anxiety in early adulthood. J Dent Res 2001;80(6):1588-92.

11. Nicolas E, Collado V, Faulks D, Bullier B, Hennequin M. A national cross-sectional survey of dental anxiety in the French adult population. BMC Oral Health 2007;7:12.

12. Al-Omari WM, Al-Omiri MK. Dental anxiety among university students and its correlation with their field of study. J Appl Oral Sci 2009;17(3):199- 203.

13. Erten H, Akarslan ZZ, Bodrumlu E. Dental fear and anxiety levels of patients attending a dental clinic. Quintessence Int 2006;37(4):304-10.

14. Firat D, Tunc EP, Sar V. Dental anxiety among adults in Turkey. J Contemp Dent Pract 2006;7(3):7582.

15. Humphris GM, Clarke HM, Freeman R. Does completing a dental anxiety questionnaire increase anxiety? A randomized controlled trail with adults in general dental practice. Br Dent J 2006; 201(1):33-35.

16. Gisler V, Bassetti R, Mericske-Stern R, Bayer S, Enkling N. A cross-sectional analysis of the prevalence of dental anxiety and its relation to the oral health-related quality of life in patients with dental treatment needs at a university clinic in Switzerland. Gerodontology 2012;29(2):e290-6.

17. Ng SK, Leung WK. A community study on the relationship of dental anxiety with oral health status and oral health-related quality of life. Community Dent Oral Epidemiol 2008;36(4):347-56.

18. Armfield JM. How do we measure dental fear and what are we measuring anyway? Oral Health Prev Dent 2010;8(2):107-15.

19. Dailey YM, Humphris GM, Lennon MA. The use of dental anxiety questionnaires: a survey of a group of UK dental practitioners. Br Dent J 2001;190(8):450-3.

20. Halonen H, Salo T, Hakko H, Rasanen P. Association of dental anxiety to personality traits in a general population sample of Finnish University students. Acta Odontol Scand 2012;70(2):96-100. 
21. Kaakko T, Milgrom P, Coldwell SE, Getz T, Weinstein P, Ramsay DS. Dental fear among university students: implications for pharmaco- logical research. Anesth Prog 1998;45(2):62-7.

22. Arslan S, Ülker M, Elmalı F, Öztürk A, Günay O. Diş hekimliği fakültesi öğrencilerinde çürük prevelansı, ağız diş sağlığı tutum ve davranışları ve dental anksiyetenin belirlenmesi. Ankara Üni Diş Hek Fak Derg 35(2) 53-60, 2008.

23. Ergüven SS, Işık B, Kılınç Y. Diş hekimliği fakültesi birinci öğrencileri ile son sınıf öğrencilerinin dental kaygı-korku düzeylerinin karşılaştırmalı olarak değerlendirilmesi. Acta Odontol Turc 2013;30(2):70-6. 